\title{
Plasma-Assisted Chemical Vapor Deposition of Titanium Oxide Layer at Room-Temperature
}

\author{
Satoshi Yamauchi*, Hiromi Suzuki, Risa Akutsu \\ Department of Biomolecular Functional Engineering, Ibaraki University, Hitachi, Japan. \\ Email: *ysatoshi@mx.ibaraki.ac.jp
}

Received November $9^{\text {th }}, 2013$; revised December $9^{\text {th }}, 2013$; accepted December $16^{\text {th }}, 2013$

Copyright (C) 2014 Satoshi Yamauchi et al. This is an open access article distributed under the Creative Commons Attribution License, which permits unrestricted use, distribution, and reproduction in any medium, provided the original work is properly cited. In accordance of the Creative Commons Attribution License all Copyrights (C) 2014 are reserved for SCIRP and the owner of the intellectual property Satoshi Yamauchi et al. All Copyright (C) 2014 are guarded by law and by SCIRP as a guardian.

\begin{abstract}
Plasma-assisted chemical vapor deposition (PCVD) at pressure as low as 3 mtorr using titanium-tetra-isopropoxide (TTIP) and oxygen mixed gas plasma generated by $13.56 \mathrm{MHz}$ radio frequency power (RF-power) below $70 \mathrm{~W}$ were applied to deposit titanium-oxide layer at temperature under $40^{\circ} \mathrm{C}$. Plasma optical emission spectroscopy and FTIR indicated that density of $\mathrm{OH}$ group in the amorphous layer was related to the density of $\mathrm{OH}$ or $\mathrm{H}_{2} \mathrm{O}$ in the plasma and the species was formed on electrode to induce the RF-power. Hydrophilicity on the layer was dependent on the density of chemisorbed $\mathrm{OH}$, but was degraded by the excess $\mathrm{OH}$. The $\mathrm{PCVD}^{-T i O_{x}}$ coating was demonstrated on polyethylene terephthalate and showed good hydrophilic property with the contact angle of water about $5^{\circ}$.
\end{abstract}

\section{KEYWORDS}

\section{PCVD; Amorphous Titanium-Oxide; FTIR; Hydroxyl; Hydrophilicity}

\section{Introduction}

Titanium dioxide $\left(\mathrm{TiO}_{2}\right)$ has been extensively investigated in view of photo-induced applications using the photo-catalytic reactions and the hydrophilicity [1,2], in addition to electronic and optoelectronic applications $[3,4]$. Especially, anatase- $\mathrm{TiO}_{2}$ is preferred for the photo-induced applications because of higher surface reaction during UV-irradiation than another crystal structures (brookite, rutile) [5]. It has been well recognized that the photocatalytic reaction inducing UV-light irradiation on the $\mathrm{TiO}_{2}$ surface is related to the $\mathrm{Ti}^{3+}$-sites which are reduced from the surface $\mathrm{Ti}^{4+}$ by photoexcited electrons, accompanying oxygen vacancies generated by the photo-excited holes [6]. The $\mathrm{Ti}^{3+}$-sites at the photo-activated $\mathrm{TiO}_{2}$ surface, which adsorb $\mathrm{OH}$ by the redox reaction for $\mathrm{H}_{2} \mathrm{O}$ molecules and generate bridging $-\mathrm{OH}$, resulted in the super-hydrophilicity. In the sequence, it is basically important to control the crystallinity of $\mathrm{TiO}_{2}$ including impurity concentration and surface morphology. For the

${ }^{*}$ Corresponding author. synthesis, a low wet- $[7,8]$ or dry-process [9-11] has been applied to enhance the photo-induced property. Plasma-assisted chemical vapor deposition (PCVD) that is expected to have some advantages for the low temperature deposition, control of the grain structure, step coverage and so on has also been a candidate for suitable synthesis process of the $\mathrm{TiO}_{2}$ films. In the process, titanium tetra-iso-propoxide (TTIP) seems to be more sufficient as preliminary precursor than titanium tetrachloride $\left(\mathrm{TiCl}_{4}\right)$ in view of contamination in the layers [12]. Previously, we demonstrated the PCVD of anatase- $\mathrm{TiO}_{2}$ for highly hydrophilic performance at $380^{\circ} \mathrm{C}$ using TTIP and $\mathrm{O}_{2}$ [13], in which the deposition was achieved in low pressure of 3 mtorr by the plasma-cracked precursors and the thermal dissociation of TTIP on the surface. However, the hydrophilic property was degraded with decreasing deposition temperature and not responsible to UV-irradiation on the amorphous layer deposited at low temperatures under $280^{\circ} \mathrm{C}$. On the other, Nakamura et al. reported an interesting result that amorphous $\mathrm{TiO}_{\mathrm{x}}$ layers deposited by PCVD at low temperatures around $150^{\circ} \mathrm{C}$ 
show good hydrophilicity after UV-irradiation [14]. They suggested that the hydroxyls including in the layer play an important role for the hydrophilicity. The result expects that amorphous $\mathrm{TiO}_{x}$ layer with hydrophilic conversion by UV-irradiation can be deposited at roomtemperature, which is required to perform hydrophilic coatings on organic materials such as PET, resin etc., but the deposition condition has to be precisely optimized with investigation of the decomposition sequence because the adsorptions such as water, hydroxyl and/or hydrocarbons frequently occur with high sticking-coefficient.

In this paper, amorphous $\mathrm{TiO}_{\mathrm{x}}$ layer at near roomtemperature under $50^{\circ} \mathrm{C}$ using TTIP and oxygen gas was demonstrated by PCVD in the low pressure of 3 mtorr investigating the reactive species to enhance the decomposition of TTIP optimizing the deposition condition for the hydrophilic performance. FTIR measurements were also carried out to evaluate residual impurities such as hydroxyls and hydrocarbons.

\section{Experimental}

\subsection{Deposition of $\mathrm{TiO}_{\mathrm{x}}$ Layer}

A conventional bell-jar type reactor with the base pres-sure under $1 \times 10^{-5}$ torr was used for plasma- assisted chemical vapor deposition (PCVD) of titaniumoxide. Schematic details of the apparatus was shown elsewhere [13]. DC-coil was settled around the bell-jar to induce DC-magnetic field during the deposition. Titanium tetra-iso-propoxide (TTIP, $\mathrm{Ti}\left(\mathrm{O}-\mathrm{i}-\mathrm{C}_{3} \mathrm{H}_{7}\right)_{4}$ : 99.7\%purity) used as preliminary precursor was charged into a quartz cell and vaporized at $70^{\circ} \mathrm{C}$ to introduce into the reactor through a stainless tube without any carrier gas, where the liquid-phase TTIP was preliminary purified at $50^{\circ} \mathrm{C}$ in vacuum for $3 \mathrm{hrs}$ before the deposition. Pure oxygen gas (99.9999\%-purity) was also introduced for the deposition. The supply ratio of $\mathrm{O}_{2} / \mathrm{TTIP}$ was controlled by monitoring the reactor pressure using Shultz gage when the TTIP and the $\mathrm{O}_{2}$ was individually introduced into the reactor. Radio-frequency power (RFpower) at $13.56 \mathrm{MHz}$ was applied through an inductively coupled rf-electrode to discharge the gases in the reactor, where the mixed gas plasma was generated in the pressure as low as 3 mtorr and stabilized by DC-magnetic field of 3000 Gauss. Si-wafers with mirror-surface used as substrates were rinsed in deionized water and dried after removal of contamination on the surface by methanol, and then mounted on a holder with a water cooling sys-tem. Prior to the deposition, the reactor was cleaned by oxygen gas plasma excited by $100 \mathrm{~W}$ rf-power with closing shutter settled above substrate to remove residual gases such as adsorbed water on the inner wall, then the substrates were exposed in oxygen-gas plasma excited by $50 \mathrm{~W}$ RF-power for $5 \mathrm{~min}$ at room- temperature. $\mathrm{TiO}_{\mathrm{x}}$ layer with the thickness about $400 \mathrm{~nm}$ was deposited at the temperature under $40^{\circ} \mathrm{C}$ which was monitored by a thermo-couple.

\subsection{Evaluation}

Thickness of the layer was checked by a surface profiler (DEKTAK150). Hydrophilicity on the layer was evaluated by the contact angle of water when $10 \mu \mathrm{L}$ deionized water was drop on the layer in air with 50\%-humidity at $2^{\circ} \mathrm{C}$. A black-light with the peak wavelength at $365 \mathrm{~nm}$ and the light power density of $1 \mathrm{~mW} / \mathrm{cm}^{2}$ was used for UV-irradiation in air on the $\mathrm{TiO}_{\mathrm{x}}$ surface. Residual impurities such as hydroxyls and hydrocarbons in the layers were evaluated by a FTIR system (JASCO FT/IR-420). Optical emission spectroscopy of plasma in the reactor was also carried out by UV-Vis spectrometer (OCEAN OPTICS: USB-2000) though a quartz-window on the cell.

\section{Results and Discussions}

\subsection{Dependence on $\mathrm{O}_{2}$ /TTIP Supply Ratio}

Figure 1 shows deposition rate of $\mathrm{TiO}_{\mathrm{x}}$ layer by induced RF-power of $30 \mathrm{~W}$ as a function of TTIP pressure $\left(\mathrm{P}_{\mathrm{TTIP}}\right)$ in the bottom axis and $\mathrm{O}_{2}$ pressure $\left(\mathrm{P}_{\mathrm{O}_{2}}\right)$ in the top axis during the deposition. In the process, the layers were deposited in 3 mtorr with a constant exhaust rate, that is, the deposition in the $\mathrm{P}_{\text {TTIP }}$ of 3 mtorr was performed without $\mathrm{O}_{2}$ supply. The deposition rate was uniquely increased with the $\mathrm{P}_{\text {TTIP }}$, which indicates the deposition was limited by TTIP supply rate, but saturated above 2 mtorr. Plasma optical emission spectra was quite different by $\mathrm{O}_{2}$ supply as shown in Figure 2, in which the spectrum of $\mathrm{O}_{2}$ plasma is shown in $1 / 5$-scale and the

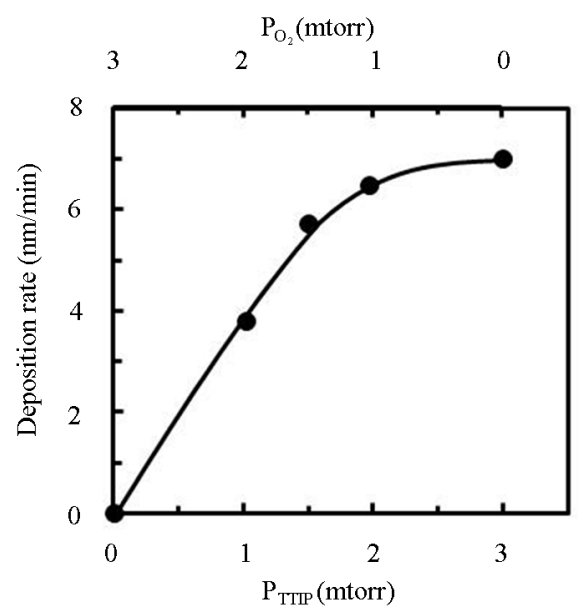

Figure 1. Dependence of $\mathrm{TiO}_{\mathrm{x}}$ deposition rate on TTIPpressure $\left(\mathrm{P}_{\text {TTIP }}\right.$ : bottom axis) and $\mathrm{O}_{2}$-pressure $\left(\mathrm{P}_{\mathrm{O}_{2}}\right.$ : top axis). 
TTIP $+\mathrm{O}_{2}$ plasma was generated by the $\mathrm{P}_{\text {TTIP }}$ of 1.5 mtorr $\left(\mathrm{P}_{\mathrm{TTIP}} / \mathrm{P}_{\mathrm{O}_{2}}=1\right)$. Typical emissions due to excited oxygen, hydrogen, carbon-oxides and hydroxyl were observed in the TTIP $+\mathrm{O}_{2}$ plasma, however, any emission due to excited oxygen could not be detected in the TTIP plasma. The emission spectra suggested TTIP was not only dissociated in TiO-R but also in Ti-OR because the $\mathrm{CO}_{2}$ and $\mathrm{OH}$ emissions could be observed in the TTIP plasma without the emissions due to $\mathrm{O}$ and $\mathrm{O}_{2}$. It is considered that the decomposition sequence was similar to the previous report for PCVD performed in 350 mtorr, in which it was suggested that TTIP can be decomposed by electron impact to $\mathrm{Ti}$ and $\mathrm{TiO}_{\mathrm{x}}$ in vapor-phase of TTIP $+\mathrm{O}_{2}$ plasma and then oxidized by O-radical in the vapor phase or on the deposition surface [15]. However, TTIP was scarcely dissociated in the vapor phase at low pressure of 3 mtorr as discussed by the dependence on RF-power in Section 3.2. Figure 3 shows dependence of the emission intensity due to the excited species on the

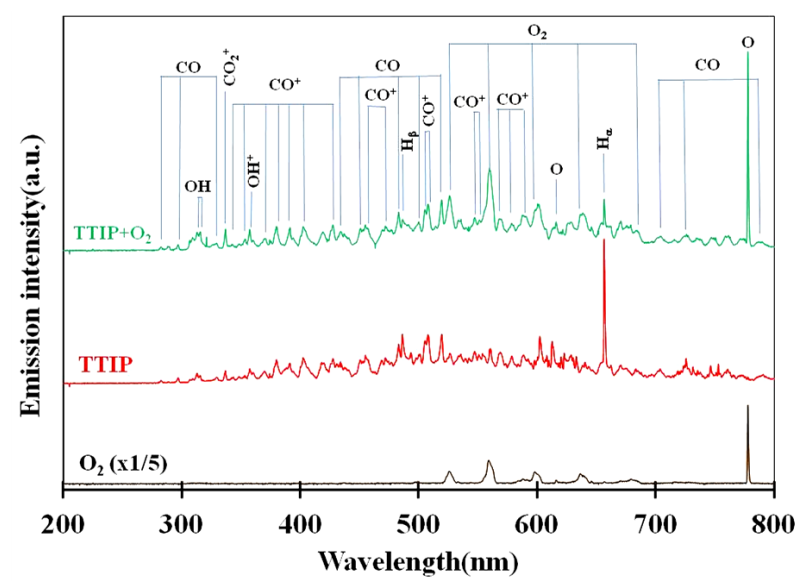

Figure 2. Optical emission spectra of $\mathrm{O}_{2}$ plasma (black-line), TTIP plasma (red-line) and $\mathrm{O}_{2}+$ TTIP plasma (green-line).

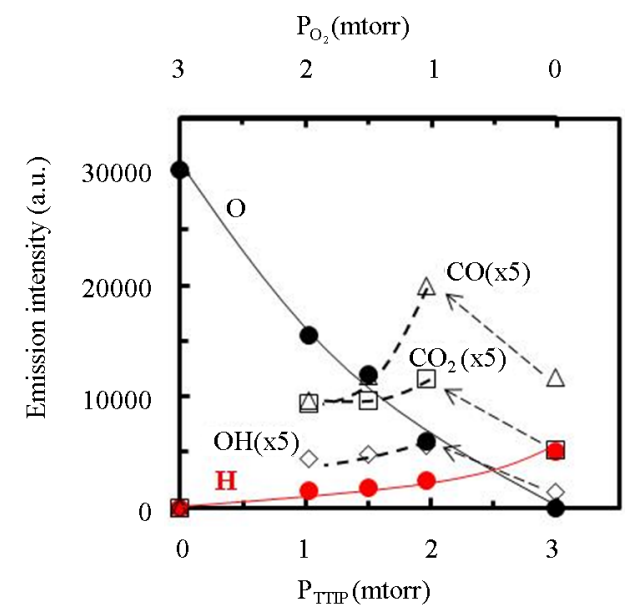

Figure 3. Dependence of optical emission spectra due to excited species in the plasma on the $P_{\text {TTIP }}$ and $P_{\mathrm{O}_{2}}$. gas supply rate shown by $\mathrm{P}_{\mathrm{TTIP}}$ and $\mathrm{P}_{\mathrm{O}_{2}}$, where the intensities of $\mathrm{CO}, \mathrm{CO}_{2}$ and $\mathrm{OH}$ were extended by 5 -times. The intensity of $\mathrm{O}$ and $\mathrm{H}$ were gradually increased and decreased with $\mathrm{P}_{\mathrm{O}_{2}}$ (decreasing $\mathrm{P}_{\text {TTIP }}$ ), respectively. In contrast, the emissions due to $\mathrm{CO}, \mathrm{CO}_{2}$ and $\mathrm{OH}$ were significantly increased by $\mathrm{O}_{2}$ supply comparing to the TTIP plasma as shown by bow-lines and then gradually decreased with decreasing TTIP supply rate. The result could be recognized that $\mathrm{CO}$ and $\mathrm{H}$ were oxidized by excited oxygen. Commonly, it is expected that $\mathrm{OH}$ or $\mathrm{H}_{2} \mathrm{O}$ can play a role to enhance TTIP dissociation as demonstrated in Sol-Gel process, which is resulted in the formation of Ti-OH and the oxo-bridging of Ti-O-Ti [16]. It is however seemed in this work that not only $\mathrm{OH}$ but also the other species influenced to the dissociation because the deposition rate by using TTIP plasma was comparable in the plasma to that by using TTIP $+\mathrm{O}_{2}$ plasma with the $\mathrm{P}_{\text {TTIP }}=2.0$ mtorr whereas the emission due to $\mathrm{OH}$ was significantly increased in the TTIP $+\mathrm{O}_{2}$ plasma comparing to that in the TTIP plasma. Previously, it was reported by FTIR studies for TTIP dissociation that atomic oxygen radicals supplied from oxygen remote-plasma enhance the dissociation of TTIP and the dissociation energy is decreased to $27.3 \mathrm{~kJ} / \mathrm{mol}$ [17]. In contrast, the energy for the dissociation in the PCVD was $4.5 \mathrm{~kJ} / \mathrm{mol}$ as shown elsewhere [13]. The significantly low dissociation energy in the PCVD comparing to the remote-plasma assisted deposition suggested that charged particles such as electrons and ions were also contributed to the dissociation.

Figure 4 shows FTIR absorption spectra of the $\mathrm{TiO}_{\mathrm{x}}$ layers deposited by $\mathrm{P}_{\mathrm{TTIP}}$ of (a) 2.0, (b) 1.5, and (c) 1.0 mtorr, where the $\mathrm{P}_{\mathrm{O}_{2}} / \mathrm{P}_{\text {TTIP }}$ was $0.5,1.0$ and 2.0 respectively. Broad-absorptions around $500 \mathrm{~cm}^{-1}$, which are recognized due to short-range O-Ti-O network in amorphous $\mathrm{TiO}_{\mathrm{x}}$ [15], were observed in the all samples and the intensity was scarcely dependent on the $\mathrm{P}_{\mathrm{O}_{2}}$

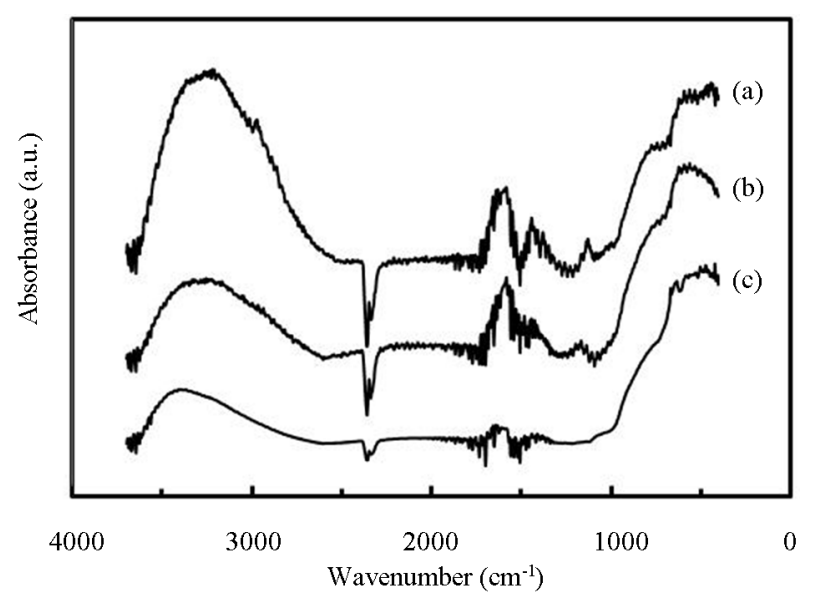

Figure 4. FTIR spectra of $\mathrm{TiO}_{\mathrm{x}}$ layers deposited by $\mathbf{P}_{\mathrm{TTIP}}$ of (a) 2.0, (b) 1.5 and (c) 1.0 mtorr. 
$/ \mathrm{P}_{\text {TTIP }}$ ratio. In addition, absorptions at 1410, 2850 and $2950 \mathrm{~cm}^{-1}$, which is attributed to $-\mathrm{CH}_{2}$ (bending), $-\mathrm{CH}_{3}$ (stretching) and $-\mathrm{CH}_{2}$ (stretching) respectively [18], were observed in the spectrum (a), but the intensity were notably decreased with increasing the $\mathrm{P}_{\mathrm{O}_{2}} / \mathrm{P}_{\text {TTIP }}$ ratio and could not be observed in the spectrum (b) and (c). The broad-spectrum below $2600 \mathrm{~cm}^{-1}$ can be assigned to absorptions due to $\mathrm{H}_{2} \mathrm{O}$ or $\mathrm{OH}$ [18]. In addition, broad-spectrum below $2600 \mathrm{~cm}^{-1}$ was clearly observed and the feature was significantly decreased with increasing $\mathrm{P}_{\mathrm{O}_{2}} / \mathrm{P}_{\text {TTIP }}$ ratio. It is noted that the broad-spectrum was shifted toward higher wavenumber with increasing the ratio, which indicated the spectrum consists of some spectra. Figure 5 shows the absorption spectra above $2600 \mathrm{~cm}^{-1}$ in the layers deposited by $\mathrm{P}_{\text {TTIP }}$ of (a) 2.0, (b) 1.5 and (c) 1.0 mtorr with the deconvoluted spectra (blue-line) and the fitted curve (red-line), where Gaussian function was used for the deconvolution. The spectrum could be well reconstructed by four spectra peak at 3015, 3251, 3418 and $3530 \mathrm{~cm}^{-1}$ which could be attributed to the absorptions due to physisorbed $\mathrm{H}_{2} \mathrm{O}$ (around $3008 \mathrm{~cm}^{-1}$ ) [19], chemisorbed $\mathrm{OH}$ to $\mathrm{Ti}$ (around 3200 $\mathrm{cm}^{-1}, 3400 \mathrm{~cm}^{-1}$ ) [20] and $\mathrm{H}_{2} \mathrm{O}_{2}$ (around $3537 \mathrm{~cm}^{-1}$ ) [21]. Figure 6(a) shows dependence of the integrated intensity related to the hydroxyls on $\mathrm{P}_{\text {TTIP }}$. The absorptions were significantly increased with TTIP supply rate (decreasing $\mathrm{O}_{2}$ /TTIP ratio). The feature could be simply described by $\mathrm{OH}$ emission intensity in the plasma as shown in Figure 6(b), where the absorption intensity (ABS) was divided by the deposition period (Depo. period). The result linearly dependent on the $\mathrm{OH}$ emission intensity clearly indicated the absorption species due to hydroxyls were formed by $\mathrm{OH}$ or $\mathrm{H}_{2} \mathrm{O}$ in the plasma. In addition, the (ABS)/(Depo. period) for the species was asymptotic to

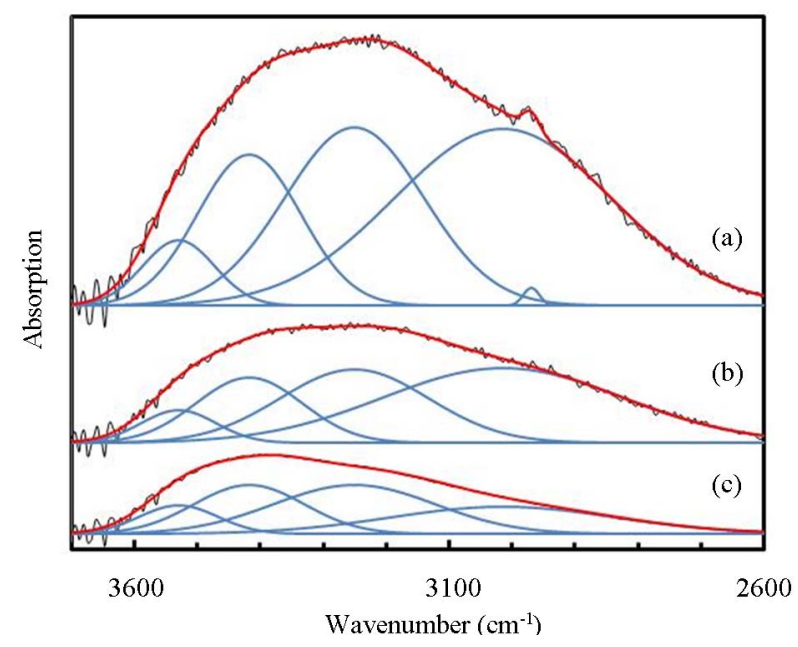

Figure 5. Broad absorption spectra above $2600 \mathrm{~cm}^{-1}$ in $\mathrm{TiO}_{\mathrm{x}}$ layer deposited by $P_{\text {TTIP }}$ of (a) 2.0, (b) 1.5 and (c) 1.0 mtorr (black-line) with the deconvoluted spectra (blue-line) and the fitted curve (red-line). the $\mathrm{OH}$ emission intensity about 850, which indicated that $\mathrm{OH}$ or $\mathrm{H}_{2} \mathrm{O}$ was also contributed to the deposition without the absorption species.

\subsection{Dependence on Induced RF-Power}

Figure 7 shows dependence of (a) deposition rate and (b) optical emission intensity on the induced RF-power, where the $\mathrm{P}_{\text {TTIP }} / \mathrm{P}_{\mathrm{O}_{2}}$ ratio was kept to $1.0\left(\mathrm{P}_{\text {TTIP }}=\mathrm{P}_{\mathrm{O}_{2}}=\right.$ 1.5 mtorr). Although any deposit could not be observed when the RF-power was not induced, the deposition rate was increased with the RF-power and then decreased by the power above $70 \mathrm{~W}$. In general, TTIP can be dissociated to the metal-oxides in the gas-phase and on the deposition surface. It was previously reported for amorphous $\mathrm{TiO}_{\mathrm{x}}$ deposition by PCVD using TTIP and $\mathrm{O}_{2}$ that the deposition rate is dependent on the density of atomic oxygen radical and decreased with increasing the induced RF-power from $5 \mathrm{~W}$ to $20 \mathrm{~W}$ in 350 mtorr because of increasing the gas-phase dissociation in the plasma [22]. In contrast, the deposition rate was increased with the RF-power below $50 \mathrm{~W}$ in this work, which is considered to be derived from the increased mean-free path in the low pressure of 3 mtorr. On the other, intensity of optical emission from the plasma was linearly increased with the RF-power. If TTIP was dissociated in the gas phase of the plasma, density of hydrogen and hydroxyls should be increased with the RF-
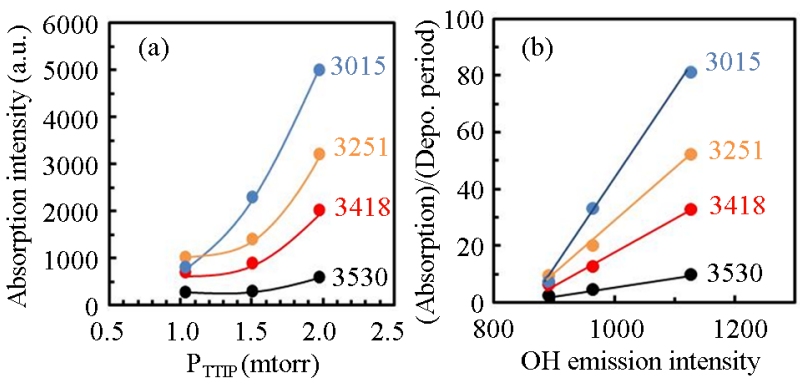

Figure 6. (a) Integrated intensity of absorptions concerned to hydroxyls in $\mathrm{TiO}_{\mathrm{x}}$ layers for $\mathbf{P}_{\mathrm{TTIP}}$ and (b) the absorption intensity divided by the deposition period for $\mathrm{OH}$ emission intensity in the plasma.
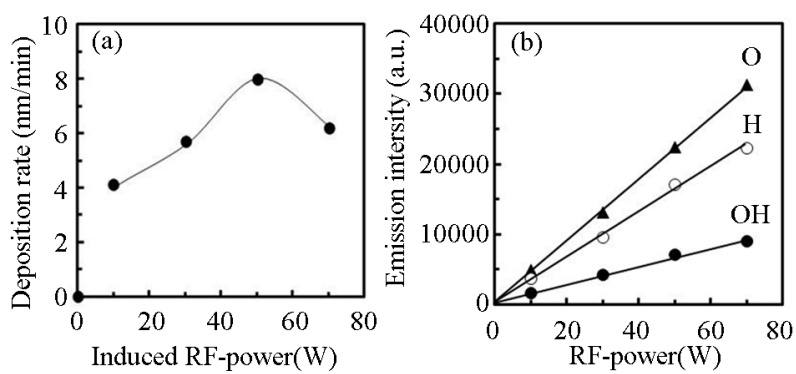

Figure 7. Dependence of (a) deposition rate and (b) optical emission intensity on the induced $R F$ power, where the supply rate of $\mathrm{P}_{\mathrm{TTIP}} / \mathrm{P}_{\mathrm{O}_{2}}$ was $1.0\left(\mathrm{P}_{\mathrm{TTIP}}=\mathrm{P}_{\mathrm{O}_{2}}=1.5 \mathrm{mtorr}\right)$. 
power, and the emission intensity should be super-linearly increased with the RF-power because the emission intensity was expected to be in proportion to the density of particle and the electron density in the gas phase. Therefore, it is concluded from the result that not only oxygen density but also hydrogen and hydroxyls density were not dependent on the RF-power. In the process introducing RF-power through the electrode settled in reactor, the gases can be efficiently dissociated on the electrode, in which the density of the dissociated species are fundamentally dependent on the density of precursor in the reactor.

Figure 8 show FTIR spectra of PCVD-TiO ${ }_{x}$ layers deposited by RF-power of (a) 10, (b) 30, (c) 50 and (d) $70 \mathrm{~W}$, where the PTTIP was 0.15 mtorr. The feature of the broad-absorption below $2600 \mathrm{~cm}^{-1}$ was dependent on the RF-power. Figure 9 show variations of (a) integrated intensity of deconvoluted FTIR spectra for the OH-related absorptions and (b) (ABS)/(Depo. Period) for the RF-power, where the thickness of layers were about $400 \mathrm{~nm}$ in the samples. Absorptions due to $\mathrm{CH}_{\mathrm{x}}$ were not observed in the samples. The absorption due to physisorbed $\mathrm{H}_{2} \mathrm{O}$ around $3530 \mathrm{~cm}^{-1}$ was gradually decreased

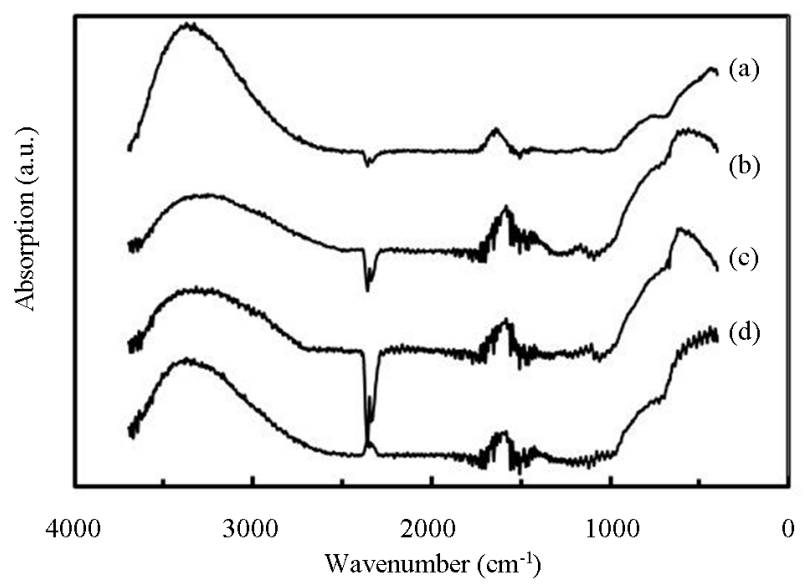

Figure 8. FTIR spectra of $\mathrm{TiO}_{\mathrm{x}}$ layers deposited by RFpower of (a) 10, (b) 30 , (c) 50 and (c) $70 \mathrm{~W}$, where $P_{\text {TTIP }}$ was 1.5 mtorr.
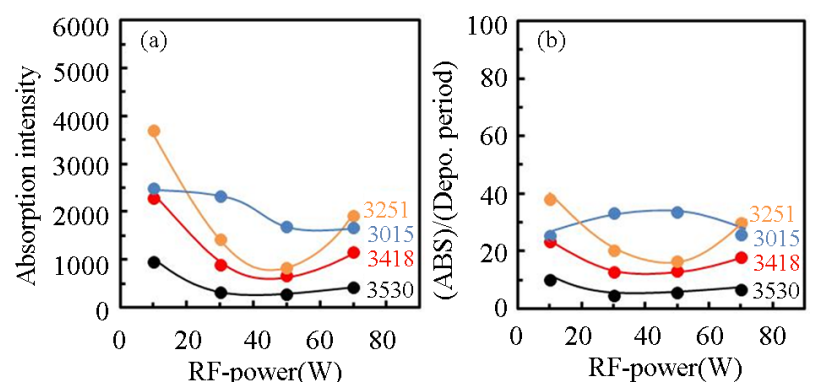

Figure 9. Variation of (a) integrated intensity of deconvoluted $\mathrm{OH}$-related absorptions in $\mathrm{TiO}_{\mathrm{x}}$ layers and the intensity divided by the deposition rate for induced RF-power. with increasing RF-power whereas density of $\mathrm{OH}$ or $\mathrm{H}_{2} \mathrm{O}$ was not dependent on the RF-power. In contrast, the other absorptions were decreased with increasing RF-power but increased by the RF-power of $70 \mathrm{~W}$. For the (ABS)/ (Depo. Period), the physisorbed $\mathrm{H}_{2} \mathrm{O}$ was slightly increased with the RF-power but decreased by the RFpower of $70 \mathrm{~W}$. On the other, the (ABS)/(Depo. Period) due to chemisorbed $\mathrm{OH}$ were minimized by the RFpower of $30-50 \mathrm{~W}$. It has been well recognized that TTIP is easily dissociated to $\mathrm{Ti}-(\mathrm{OH})_{\mathrm{x}}$ at room-temperature by water contribution [16]. The hydrolysis was also included in the PCVD process, especially, in the case of low RF-power such as $10 \mathrm{~W}$, in which the supplied $\mathrm{H}_{2} \mathrm{O}$ was partially consumed to dissociate TTIP. On the other, it is considered that the contribution of electron and/or excited species such as radicals and ions should be taken into account to the deposition sequence, for example, in Ti-O-Ti network formation from $\mathrm{Ti}-\mathrm{OH}$ and in dissociation of supplied $\mathrm{H}_{2} \mathrm{O}$ on the deposition surface. Therefore, the density of Ti-OH was decreased with the RF-power and that of $\mathrm{H}_{2} \mathrm{O}$ was decreased by the RF-power of $70 \mathrm{~W}$. It is noted here that when electrons are supplied to the deposition surface, however, Ti-O-Ti is dissociated to Ti-O, Ti be-cause the $\mathrm{Ti}^{4+}$ is reduced to $\mathrm{Ti}^{3+}$, and then Ti-OH is formed by supplied $\mathrm{H}$ and $\mathrm{OH}$. As a result, density of $\mathrm{Ti}-\mathrm{OH}$ was increased with the RF-power above $50 \mathrm{~W}$.

\subsection{Hydrophilicity}

Figures 10 show contact angle of water $\left(\theta_{\text {water }}\right)$ on $\mathrm{TiO}_{\mathrm{x}}$ layer deposited by (a) various TTIP supply rate $\left(\mathrm{P}_{\mathrm{TTIP}}\right)$ and (b) various RF-power, where the $\theta_{\text {water }}$ was evaluated after UV-irradiation for 1 hour (black-circles) and then after exposure in air for 2-weeks (red-circles). $\theta_{\text {water }}$ was decreased with decreasing $\mathrm{P}_{\text {TTIP }}$ (increasing $\mathrm{P}_{\mathrm{O}_{2}}$ $\left./ \mathrm{P}_{\text {TTIP }}\right)$. In contrast, $\theta_{\text {water }}$ was decreased with the RF-power but increased on the layers deposited by the RF-power above $50 \mathrm{~W}$. Although amorphous $\mathrm{TiO}_{\mathrm{x}}$ deposited at relatively high temperature above $250^{\circ} \mathrm{C}$ is not in response to UV-irradiation [16] for the hydrophilicity,
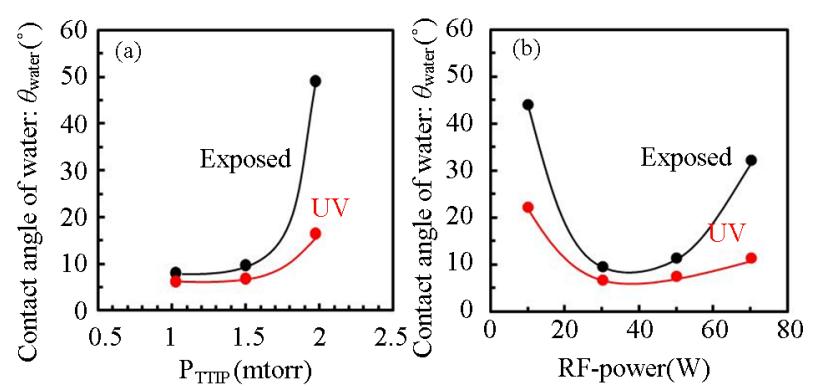

Figure 10. Contact angle of water on $\mathrm{TiO}_{\mathrm{x}}$ layer deposited by various (a) $\mathbf{P}_{\text {TTIP }}$ and (b) RF power after UV-irradiation (red-circles) and after exposure for 2-weeks in air (blackcircles). 
the contact angle of water $\mathrm{OH}$-included amorphous $\mathrm{TiO}_{\mathrm{x}}$ layer is significantly decreased by UV-irradiation [17]. Therefore, it is considered that $\mathrm{OH}$ species play a role for hydrophilicity on the layers deposited in this work. Figure 11 shows dependence of $\operatorname{Cos}\left(\theta_{\text {water }}\right)$ on the integrated absorption intensity in $\mathrm{TiO}_{\mathrm{x}}$ layers grown by various $\mathrm{P}_{\text {TTIP }}$ and RF-power, in which the absorption intensity is divided by the layer thickness to estimate the density of the species on the surface. In this work, the $\operatorname{Cos}\left(\theta_{\text {water }}\right)$ was linearly increased with decreasing chemisorbed $\mathrm{OH}$ density but seemed to be not dependent on the physisorbed $\mathrm{H}_{2} \mathrm{O}$. In addition, the intensity due to $\mathrm{H}_{2} \mathrm{O}_{2}$ (3530) was asymptotic to zero at the $\operatorname{Cos}\left(\theta_{\text {water }}\right)=1.0$ but the intensity due to chemisorbed $\mathrm{OH}(3418,3251)$ was not asymptotic to zero at the $\operatorname{Cos}\left(\theta_{\text {water }}\right)=1.0$. The result indicated that chemisorbed $\mathrm{OH}$ is necessary for the super-hydrophilicity but the excess species are not suitable for the purpose because of decreasing the Ti-O-Ti network. Especially, $\mathrm{H}_{2} \mathrm{O}_{2}$ which is expected to be included as Ti-OH-HO-Ti should be removed from the layers.

The PCVD- $\mathrm{TiO}_{\mathrm{x}}$ coating at room-temperature was demonstrated on polyethylene terephthalate (PET). Figure 12 shows features of water droplets on (a) PET and (b) $\mathrm{PCVD}^{-\mathrm{TiO}_{\mathrm{x}}}$ layer deposited on PET by optimized condition $\left(\mathrm{P}_{\mathrm{TTIP}}=1.5 \mathrm{mtorr}\right.$, $\mathrm{RF}$ power $\left.=30 \mathrm{~W}\right)$, where the water was dropped on the $\mathrm{TiO}_{\mathrm{x}}$ layer after UV-irradiation for 1 hour. It is noted that any deformation of the

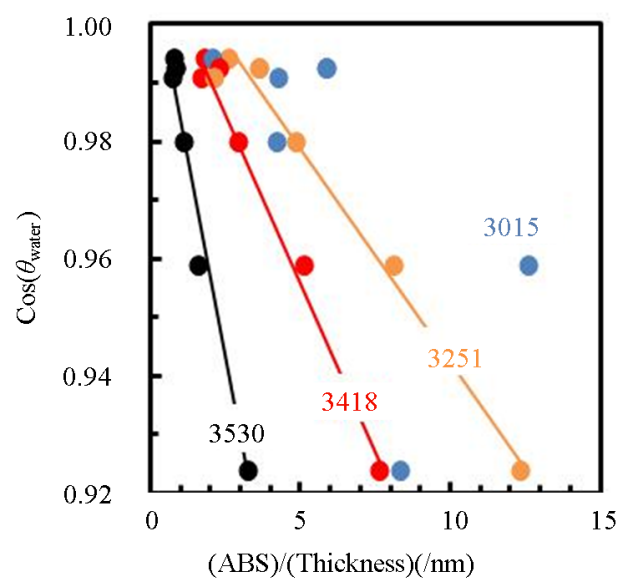

Figure 11. Dependence of $\operatorname{Cos}\left(\theta_{\text {water }}\right)$ on OH-related absorption intensity, where the absorption intensity in the layer (ABS) is divided by the layer thickness (thickness).

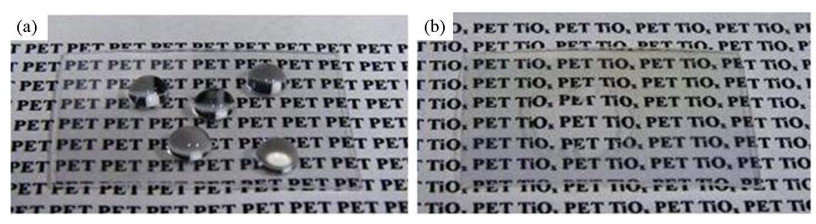

Figure 12. Feature of water droplets on (a) PET and (b) PCVD-TiO $_{x} /$ PET, in which water of $10 \mu \mathrm{L}$ was dropped on

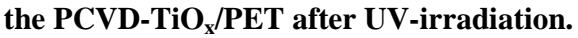

PET was not observed after the $\mathrm{TiO}_{\mathrm{x}}$ deposition. Whereas the $\theta_{\text {water }}$ was $75^{\circ}$ on the PET, the angle was decreased to $5^{\circ}$ on the $\mathrm{TiO}_{\mathrm{x}}$ layer. The $\theta_{\text {water }}$ on the $\mathrm{TiO}_{\mathrm{x}}$ layer is slightly small comparing to that on $\mathrm{TiO}_{\mathrm{x}}$ layer deposited on Si substrate, which was probably derived from the difference of surface roughness. As demonstrated here, the PCVD process at room-temperature can be concluded to be useful for hydrophilic coating on the materials with poor thermal resistance.

\section{Conclusion}

Plasma-assisted deposition of $\mathrm{TiO}_{\mathrm{x}}$ layer at room temperature using TTIP and $\mathrm{O}_{2}$ gas plasma was studied by FTIR and plasma optical emission spectroscopy. $\mathrm{OH}$ content in the layer was significantly related to $\mathrm{OH}$ density in the plasma. Optical emission spectroscopy indicated that $\mathrm{OH}$ density in the plasma was increased by $\mathrm{O}_{2}$ supply but not dependent on the induced RF-power, which suggested that TTIP was scarcely dissociated in the plasma at pressure as low as 3 mtorr but efficiently dissociated on RF-electrode. Chemisorbed $\mathrm{OH}$, especially $\mathrm{H}_{2} \mathrm{O}_{2}$ in the layer was significantly influenced on the hydrophilicity. The PCVD-TiO coating was demonstrated on PET and the contact angle of water was decreased to $5^{\circ}$ compared with $75^{\circ}$ on PET.

\section{REFERENCES}

[1] R. Wang, K. Hashimoto and A. Fujishima, "Light-Induced Amphiphilic Surfaces,” Nature, Vol. 388, No. 6641, 1997, pp. 431-432. http://dx.doi.org/10.1038/41233

[2] A. Mills, A. Lepre, N. Elliott, A. Bhopal, I. P. Parkin and S. A. Neill, "Characterisation of the Photocatalyst Pilkington Activ ${ }^{\mathrm{TM}}$ : A Reference Film Photocatalyst?” Journal of Photochemistry and Photobiology A: Chemistry, Vol. 160, No. 3, 2003, pp. 213-224. http://dx.doi.org/10.1016/S1010-6030(03)00205-3

[3] S. A. Campbell, H. S. Kim, D. C. Gilmer, B. He, T. Ma and W. L. Gladfelter, "Titanium Dioxide $\left(\mathrm{TiO}_{2}\right)$-Based Gate Insulators,” IBM Journal of Research and Development, Vol. 43, No. 3, 1999, pp. 383-392.

http://dx.doi.org/10.1147/rd.433.0383

[4] C. Martinet, V. Paillard, A. Gagnaire and J. Joseph, “Deposition of $\mathrm{SiO}_{2}$ and $\mathrm{TiO}_{2}$ Thin Films by Plasma Enhanced Chemical Vapor Deposition for Antireflection Coating," Journal of Non-Crystalline Solids, Vol. 216, 1997, pp. 77-82.

http://dx.doi.org/10.1016/S0022-3093(97)00175-0

[5] H. Gerischer and H. Heller, "The Role of Oxygen in Photooxidation of Organic Molecules on Semiconductor Particles,” The Journal of Physical Chemistry, Vol. 95, No. 13, 1991, pp. 5261-5267. http://dx.doi.org/10.1021/j100166a063

[6] R. Wang, K. Hashimoto, A. Fujishima, M. Chikuni, E. Kojima, A. Kitamura, M. Shimohigoshi and T. Watanabe, "Photogeneration of Highly Amphiphilic $\mathrm{TiO}_{2}$ Surfaces," 
Advanced Materials, Vol. 10, No. 2, 1998, pp. 135-138. http://dx.doi.org/10.1002/(SICI)1521-4095(199801)10:2< 135::AID-ADMA135>3.0.CO;2-M

[7] N. Kotov, F. Meldrum and J. H. Fendler, "Monoparticulate Layers of Titanium Dioxide Nanocrystallites with Controllable Interparticle Distances,” The Journal of Physical Chemistry, Vol. 98, No. 36, 1994, pp. 8827-8830. http://dx.doi.org/10.1021/j100087a002

[8] M. Okuya, N. A. Prokudina, K. Mushika and S. Kaneko, " $\mathrm{TiO}_{2}$ Thin Films Synthesized by the Spray Pyrolysis Deposition (SPD) Technique," Journal of the European Ceramic Society, Vol. 19, No. 6, 1999, pp. 903-906. http://dx.doi.org/10.1016/S0955-2219(98)00341-0

[9] M. H. Suhail, G. Mohan Rao and S. Mohan, “dc Reactive Magnetron Sputtering of Titanium-Structural and Optical Characterization of $\mathrm{TiO}_{2}$ Films," Journal of Applied Physics, Vol. 71, No. 3, 1992, pp. 1421-1427. http://dx.doi.org/10.1063/1.351264

[10] P. Lobl, M. Huppertz and D. Mergel, "Nucleation and Growth in $\mathrm{TiO}_{2}$ Films Prepared by Sputtering and Evaporation," Thin Solid Films, Vol. 251, No. 1, 1994, pp. 72-79. http://dx.doi.org/10.1016/0040-6090(94)90843-5

[11] V. Gauthier, S. Bourgeois, P. Sibillot, M. Maglione and M. Sacilotti, "Growth and Characterization of AP-MOCVD Iron Doped Titanium Dioxide Thin Films," Thin Solid Films, Vol. 340, No. 1, 1999, pp. 175-182. http://dx.doi.org/10.1016/S0040-6090(98)01469-2

[12] S. Mathur and P. Kuhn, "CVD of Titanium Oxide Coatings: Comparative Evaluation of Thermal and Plasma Assisted Processes," Surface and Coatings Technology, Vol. 201, No. 3-4, 2006, pp. 807-814. http://dx.doi.org/10.1016/j.surfcoat.2005.12.039

[13] S. Yamauchi and Y. Imai, "Plasma-Assisted Chemical Vapor Deposition of $\mathrm{TiO}_{2}$ Thin Films for Highly Hydrophilic Performance," Crystal Structure Theory and Applications, Vol. 2, No. 1, 2013, pp. 1-7. http://dx.doi.org/10.4236/csta.2013.21001

[14] M. Nakamura, S. Kato, T. Aoki, L. Sirghi and Y. Hatanaka, "Role of Terminal OH Groups on the Electrical and Hydrophilic Properties of Hydro-Oxygenated Amorphous $\mathrm{TiO}_{\mathrm{x}}: \mathrm{OH}$ Thin Films," Journal of Applied Physics, Vol. 90, No. 7, 2001, pp. 3391-3395. http://dx.doi.org/10.1063/1.1398599
[15] L. Sirghi, T. Aoki and Y. Hatanaka, "Hydrophilicity of $\mathrm{TiO}_{2}$ Thin Films Obtained by Radio Frequency Magnetron Sputtering Deposition,” Thin Solid Films, Vol. 422, No. 1, 2002, pp. 55-61. http://dx.doi.org/10.1016/S0040-6090(02)00949-5

[16] M. Gotić, M. Ivanda, A. Sekulić, S. Musić, S. Popovi, A. Turković and K. Furić, "Microstructure of Nanosized TiO, Obtained by Sol-Gel Synthesis," Materials Letters, Vol. 28, No. 1-3, 1996, pp. 225-229. http://dx.doi.org/10.1016/0167-577X(96)00061-4

[17] K. H. Ahn, Y. B. Park and D. W. Park, "Kinetic and Mechanistic Study on the Chemical Vapor Deposition of Titanium Dioxide Thin Films by in Situ FT-IR Using TTIP,” Surface and Coatings Technology, Vol. 171, No. 1, 2003, pp. 198-204.

[18] T. Tsuchiya, A. Watanabe, Y. Imai, H. Niino, I. Yamaguchi, T. Manabe, T. Kumagai and S. Mizuta, "Direct Conversion of Titanium Alkoxide into Crystallized $\mathrm{TiO}_{2}$ (Rutile) Using Coating Photolysis Process with ArF Excimer Laser,” Japanese Journal of Applied Physics, Vol. 38, No. 7B, 1999, pp. L823-L825. http://dx.doi.org/10.1143/JJAP.38.L823

[19] J. Araña, C. Garriga i Cabo, J. M. Doña-Rodríguez, O. González-Díaz, J. A. Herrera-Melián and J. Pérez-Peña, "FTIR Study of Formic Acid Interaction with $\mathrm{TiO}_{2}$ and $\mathrm{TiO}_{2}$ Doped with Pd and $\mathrm{Cu}$ in Photocatalytic Processes," Applied Surface Science, Vol. 239, No. 1, 2004, pp. 6071.

[20] D. A. Panayotov and J. T. Yates Jr., "Depletion of Conduction Band Electrons in $\mathrm{TiO}_{2}$ by Water ChemisorptionIR Spectroscopic Studies of the Independence of Ti-OH Frequencies on Electron Concentration,” Chemical Physics Letters, Vol. 410, No. 1, 2005, pp. 11-17. http://dx.doi.org/10.1016/j.cplett.2005.03.146

[21] M. Pettersson, S. Tuominen and M. Räsänen, "Matrix Isolation and Quantum Chemical Studies on the $\mathrm{H}_{2} \mathrm{O}_{2}$ $\mathrm{SO}_{2}$ Complex," Physical Chemistry Chemical Physics, Vol. 6, No. 19, 2004, pp. 4607-4613.

[22] W. Yang and C. A. Wolden, "Plasma-Enhanced Chemical Vapor Deposition of $\mathrm{TiO}_{2}$ Thin Films for Dielectric Applications," Thin Solid Films, Vol. 515, No. 4, 2006, pp. 1708-1713. http://dx.doi.org/10.1016/j.tsf.2006.06.010 